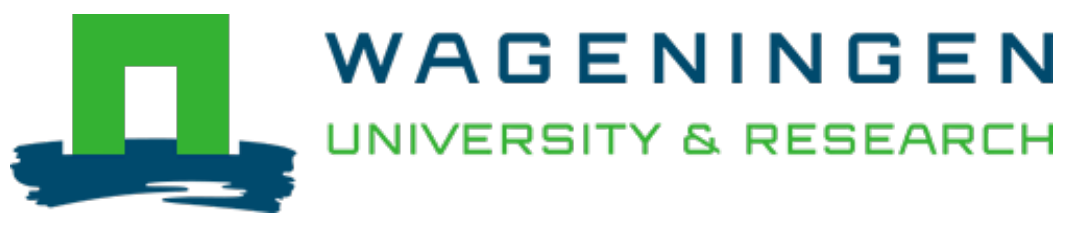

\title{
Identification of blood cell transcriptome-based biomarkers in adulthood predictive of increased risk to develop metabolic disorders using early life intervention rat models
}

\author{
FASEB Journal \\ Szostaczuk, Nara; Schothorst, Evert M.; Sánchez, Juana; Priego, Teresa; Palou, Mariona et al \\ https://doi.org/10.1096/fj.202000071RR
}

This article is made publicly available in the institutional repository of Wageningen University and Research, under the terms of article $25 \mathrm{fa}$ of the Dutch Copyright Act, also known as the Amendment Taverne. This has been done with explicit consent by the author.

Article 25 fa states that the author of a short scientific work funded either wholly or partially by Dutch public funds is entitled to make that work publicly available for no consideration following a reasonable period of time after the work was first published, provided that clear reference is made to the source of the first publication of the work.

This publication is distributed under The Association of Universities in the Netherlands (VSNU) 'Article $25 \mathrm{fa}$ implementation' project. In this project research outputs of researchers employed by Dutch Universities that comply with the legal requirements of Article 25fa of the Dutch Copyright Act are distributed online and free of cost or other barriers in institutional repositories. Research outputs are distributed six months after their first online publication in the original published version and with proper attribution to the source of the original publication.

You are permitted to download and use the publication for personal purposes. All rights remain with the author(s) and / or copyright owner(s) of this work. Any use of the publication or parts of it other than authorised under article $25 \mathrm{fa}$ of the Dutch Copyright act is prohibited. Wageningen University \& Research and the author(s) of this publication shall not be held responsible or liable for any damages resulting from your (re)use of this publication.

For questions regarding the public availability of this article please contact openscience.library@wur.nl 


\title{
Identification of blood cell transcriptome-based biomarkers in adulthood predictive of increased risk to develop metabolic disorders using early life intervention rat models
}

\author{
Nara Szostaczuk $^{1} \quad$ ～Evert M. van Schothorst ${ }^{2} \quad$ Juana Sánchez ${ }^{1,3} \quad$ Teresa Priego ${ }^{1}$ | \\ Mariona Palou $^{1,3}$ | Melissa Bekkenkamp-Grovenstein ${ }^{2}$ | Gernot Faustmann ${ }^{4,5}$ \\ Barbara Obermayer-Pietsch $^{6}$ ｜ Beate $\operatorname{Tiran}^{7}$ ｜ Johannes M. Roob ${ }^{5}$ \\ Brigitte M. Winklhofer-Roob $^{4}$ | Jaap Keijer ${ }^{2}$ | Andreu Palou ${ }^{1,3}$ | Catalina Picó S,3 $^{1,3}$ \\ ${ }^{1}$ Laboratory of Molecular Biology, Nutrition and Biotechnology (Group of Nutrigenomics and Obesity), CIBER de Fisiopatología de la Obesidad y \\ Nutrición (CIBERobn), University of the Balearic Islands, Palma de Mallorca, Spain \\ ${ }^{2}$ Human and Animal Physiology, Wageningen University, Wageningen, The Netherlands \\ ${ }^{3}$ Instituto de Investigación Sanitaria Illes Balears (IdISBa), Palma de Mallorca, Spain \\ ${ }^{4}$ Human Nutrition \& Metabolism Research and Training Center, Institute of Molecular Biosciences, Karl-Franzens University of Graz, Graz, Austria \\ ${ }^{5}$ Clinical Division of Nephrology, Department of Internal Medicine, Medical University of Graz, Graz, Austria \\ ${ }^{6}$ Division of Endocrinology, Department of Internal Medicine, Medical University of Graz, Graz, Austria \\ ${ }^{7}$ Clinical Institute of Medical and Clinical Laboratory Diagnostics, Medical University of Graz, Graz, Austria
}

\section{Correspondence}

Andreu Palou, Laboratory of Molecular Biology, Nutrition and Biotechnology

(Nutrigenomics), University of the Balearic Islands, Cra. Valldemossa Km 7.5, Palma de Mallorca 07122, Balearic Islands, Spain. Email: andreu.palou@uib.es

Funding information

EC I Seventh Framework Programme (FP7), Grant/Award Number: 244995; Ministerio de Economía y Competitividad (MINECO), Grant/Award Number: AGL2015-67019-P;

Ministerio de Ciencia, innovacion y universidades, Grant/Award Number: PGC2018-097436-B-I00; Federal Ministry of Science, Research and Economy of Austria, Grant/Award Number: BMWF651.483/0001-II/2/2010 and BMWF$651.484 / 0001-\mathrm{II} / 2 / 2010$

\begin{abstract}
Calorie restriction during gestation in rats has long-lasting adverse effects in the offspring. It induces metabolic syndrome-related alterations, which are partially reversed by leptin supplementation during lactation. We employed these conditions to identify transcript-based nutrient sensitive biomarkers in peripheral blood mononuclear cells (PBMCs) predictive of later adverse metabolic health. The best candidate was validated in humans. Transcriptome analysis of PBMCs from adult male Wistar rats of three experimental groups was performed: offspring of control dams (CON), and offspring of $20 \%$ calorie-restricted dams during gestation without (CR) and with leptin supplementation throughout lactation (CR-LEP). The expression of 401 genes was affected by gestational calorie restriction and reversed by leptin. The changes preceded metabolic syndrome-related phenotypic alterations. Of these genes, $\mathrm{Npcl}$ mRNA levels were lower in CR vs CON, and normalized to CON in CR-LEP. In humans, NPC1 mRNA levels in peripheral blood cells (PBCs) were decreased in subjects with mildly impaired metabolic health compared to healthy subjects. Therefore, a set of potential transcript-based biomarkers indicative of a predisposition to metabolic syndrome-related alterations were identified, including $\mathrm{NPCl}$, which was
\end{abstract}

\footnotetext{
Abbreviations: CON, the offspring of control dams; CR, the offspring of $20 \%$ calorie-restricted dams during gestation; CR-LEP, CR rats supplemented with leptin throughout lactation; FC, fold change; PBCs, peripheral blood cells; PBMCs, peripheral blood mononuclear cells.
} 
validated in humans. Low NPC1 transcript levels in PBCs are a candidate biomarker of increased risk for impaired metabolic health in humans.

K E Y W O R D S

gestational calorie restriction, metabolic health, metabolic programing, NPC1, PBMCs, predictive biomarkers

\section{1 | INTRODUCTION}

Prevention of chronic diseases, particularly obesity and its associated metabolic dysfunctions, is one of the major challenges in current societies. ${ }^{1}$ Diagnostic biomarkers predictive of metabolic disease risk will help prevention and management of metabolic syndrome. ${ }^{2}$ However, there is a lack of such biomarkers. Numerous studies carried out in the last decade have successfully used peripheral blood cells (PBCs), either the subfraction of mononuclear cells (peripheral blood mononuclear cells, PBMCs) or whole PBCs, as a source of candidate transcriptomic biomarkers of health and disease. ${ }^{3-5}$ The interest in these cells as a surrogate tissue is because human blood samples can be obtained in sufficient quantities with minimally invasive techniques, compared to samples of other tissues. ${ }^{6}$ Moreover, their gene expression profile reflects in part the expression profile that occurs in other tissues, such as liver and adipose tissue, and hence may reflect the physiological and pathological state of the body. ${ }^{7-10}$

The phenotypes of health or disease in adulthood are the result of the interaction between genetic and environmental factors, but metabolic programing during perinatal development also plays a key role. ${ }^{11,12}$ In fact, a growing body of evidence suggests that maternal nutritional conditions during critical stages of life may have long-term consequences for the metabolic health of the offspring, affecting their propensity to obesity in adulthood. ${ }^{11-13}$ In this context, human and animal studies associate gestational undernutrition with adverse health outcomes in adult offspring. ${ }^{13-15}$ Mechanisms underlying the dysregulation of energy homeostasis due to perinatal nutrition have been associated, among other processes, to a lower capacity to respond to insulin and leptin signaling, ${ }^{16,17}$ a perturbed hypothalamic structure and function, ${ }^{18,19}$ and a reduced innervation and functionality of white and brown adipose tissues ${ }^{20,21}$ and of the stomach. ${ }^{22}$

Hormones such as glucocorticoids, insulin, and leptin are the main candidates as early life causative factors involved in developmental programing. ${ }^{14}$ Furthermore, leptin, a natural component of breast milk, ${ }^{23}$ is considered an essential factor during lactation in the protection against the development of obesity and related pathologies in later life. ${ }^{24,25}$ Leptin supplementation of rat pups at physiological doses throughout lactation protects them against the development of age- and high-fat diet related excess body weight and other metabolic alterations. ${ }^{26,27}$ Moreover, dietary leptin supplementation to the offspring of calorie-restricted rats during gestation reverses part of the malprogramed effects associated to undernutrition during gestation. In young animals this was seen for alterations in hypothalamic structure and function, ${ }^{28}$ adipose tissue and stomach sympathetic innervation, ${ }^{29,30}$ and the altered gene expression profile in PBMCs, ${ }^{29}$ which all were largely normalized by dietary leptin supplementation.

The beneficial effects of leptin treatment during lactation preventing the detrimental effects of gestational undernutrition become phenotypically evident in adulthood, particularly in rats exposed to an obesogenic diet. ${ }^{31}$ Leptin supplementation largely prevents the higher risk of accumulating excess fat and other disturbances of the metabolic syndrome, such as insulin resistance, hypertriglyceridemia, and hepatic lipid deposition. ${ }^{31}$ Here, we made use of this rat leptin supplementation model to identify diagnostic biomarkers predictive of metabolic disease risk, that is, markers in still healthy adults predictive for their risk for metabolic disease. We compared offspring of ad libitum fed control female rats (CON) to offspring of rats exposed to mild undernutrition during gestation $(\mathrm{CR})$ and offspring of $\mathrm{CR}$ rats treated with leptin during lactation (CR-LEP). Offspring were analyzed in adulthood, prior to the manifestation of phenotypic alterations, which became apparent after 6 months. ${ }^{31}$ PBMCs were isolated and whole genome transcriptome analysis was performed, potential biomarkers were identified, a set was selected for confirmation and one of the most promising candidate biomarkers was subsequently assessed in humans, in two groups of individuals: one representing subjects with full health and the other group's subjects showing mildly impaired metabolic health.

\section{2 | MATERIALS AND METHODS}

\subsection{Animal study}

\subsubsection{Animals and experimental design}

The animal protocol followed in this study was reviewed and approved by the Bioethical Committee of the University of the Balearic Islands (Resolution Number 8453, June 2010) and guidelines for the use and care of laboratory animals of 
the University were followed in accordance with EU directive 2010/63/EU.

Animals were housed under standard conditions, with controlled temperature $\left(22^{\circ} \mathrm{C}\right)$ and a 12 hours light-dark cycle (light from 8:00 to 20:00), and had unlimited access to tap water and standard normal fat chow diet (SD) (3.3 Kcal $\mathrm{g}^{-1}$, with $8.0 \%$ calories from fat; Panlab, Barcelona, Spain). The animal protocol followed to obtain the three experimental groups was previously described in detail. ${ }^{31}$ Briefly, virgin female Wistar rats (Charles River Laboratories, Barcelona, Spain) were mated with male rats. Day of conception (day 0 of pregnancy) was determined by the presence of sperm in vaginal smear. Pregnant rats were single caged and divided into two groups: the group of control dams (CON; $n=6$ animals) was fed ad libitum with SD and the group of calorie-restricted dams (CR-dams; $n=14$ animals) was subjected to a $20 \%$ calorie restriction from day 1 to day 12 of gestation. After the calorie restriction period, all dams were fed ad libitum. On day 1 after delivery, excess pups in each litter were removed to keep 10 pups per dam as standardization. Pups born from CR-dams were randomly assigned into two groups: CR and CR-LEP. CR-LEP animals were supplemented each day throughout lactation with an oral solution of recombinant murine leptin (PeproTech, London, UK) dissolved in water, with the use of a pipette. The amount of leptin given to animals was progressively increased from $1 \mathrm{ng}$ of leptin on postnatal (PN) day 1 to $43.8 \mathrm{ng}$ on $\mathrm{PN}$ day 20, as previously described. ${ }^{31}$ $\mathrm{CON}$ and $\mathrm{CR}$ pups received the same volume of the vehicle (water). Male pups were weaned at PN day 21, and then, 8 pups from the CON group, 11 from the CR group, and 13 from the CR-LEP group were housed in groups of two animals per cage and fed with a SD.

Body weight of the animals was monitored and body fat content was measured at weaning and 4 months of age by EchoMRI-700TM; Echo Medical Systems, LLC., Houston, TX, USA.

\subsection{2 | Analysis of blood parameters}

Blood samples were collected under 12 hours fasting conditions from the saphenous vein at the age of 3 months. Serum was obtained by centrifugation of blood ( $700 \mathrm{~g}, 10$ minutes) and stored at $-20^{\circ} \mathrm{C}$ until further analysis. Blood glucose concentration was measured by Accu-Chek Glucometer (Roche Diagnostics, Barcelona, Spain). Serum levels of leptin and insulin were measured by commercial rat enzymelinked immunosorbent assay (ELISA) kits (R\&D Systems, Minneapolis, MN, USA, and Mercodia AB, Uppsala, Sweden, respectively) according to the manufacturer's instructions. The homeostatic model assessment for insulin resistance (HOMA-IR) was used to assess insulin resistance, using the formula of Matthews et al. ${ }^{32}$ HOMA-IR = fasting glucose $(\mathrm{mmol} / \mathrm{L}) \times$ fasting insulin $(\mathrm{mU} / \mathrm{L}) / 22.5$.

\subsection{3 | PBMC isolation}

Blood samples of CON, CR, and CR-LEP rats were collected from the saphenous vein at the age of 4 months under ad libitum feeding conditions and used to obtain PBMCs. Blood samples were collected using EDTA (final concentration of 3-4 $\mathrm{mM}$ ) as an anticoagulant, and then, diluted with an equal volume of buffered saline (iso-osmotic). PBMCs were immediately isolated by OptiPrep ${ }^{\mathrm{TM}}$ density-gradient separation (Sigma-Aldrich Química SA, Madrid, Spain) according to the manufacturer's instructions.

\subsection{4 | Total RNA isolation from PBMCs}

Total RNA was extracted from PBMCs by EZNA TOTAL RNA kit I (Omega Bio-Tek Inc, Norcross, GA, USA) following the manufacturer's instructions. Isolated RNA was quantified using the NanoDrop ND-1000 spechtrophotometer (NanoDrop Technologies, Ins., Wilmington, DE, USA).

\subsection{5 | Microarray processing}

RNA from PBMC samples obtained from CON, CR, and CR-LEP animals at the age of 4 months were used for gene expression microarray analysis. Quality of RNA samples was analyzed on Agilent 2100 Bioanalyzer with RNA 6000 Nano chips (Agilent Technologies, South Queensferry, United Kingdom), and all samples used for microarrays had a RNA integrity number (RIN) $\geq 8$ (a total number of 32 samples). Two hundred nanograms of RNA from each sample was reverse transcribed to complementary DNA (cDNA) using the Agilent Low Input Quick Amp Labeling kit (Agilent Technologies, Inc, Santa Clara, CA, USA), according to the manufacturer's protocol. Then, as published, ${ }^{33}$ half of the cDNA sample $(10 \mu \mathrm{L})$ was used for the linear amplification of RNA and labeling with cyanine-3 (Cy3) and the other half with cyanine-5 (Cy5), using half of the amounts indicated by the manufacturer. Transcription and labeling were carried out at $40^{\circ} \mathrm{C}$ for 2 hours, and the labeled and amplified cRNA samples were purified as previously described. ${ }^{9}$ All Cy3-labeled samples were pooled and served as a reference pool. Each sample containing $825 \mathrm{ng}$ of cRNA labeled with Cy5 and $825 \mathrm{ng}$ of Cy3 pool was hybridized on $4 \times 44 \mathrm{~K}$ G4131F whole rat genome Agilent microarrays (Agilent Technologies) for 17 hours at $65^{\circ} \mathrm{C}$ in hybridization chambers in an oven rotating at $10 \mathrm{rpm}$ (Agilent Technologies). After hybridization, the arrays were washed as previously 
described, ${ }^{9}$ following the manufacturer's protocol (Agilent Technologies).

\subsection{6 | Microarray data analysis}

An Agilent Microarray Scanner (Agilent Technologies) was used to scan the arrays. The scanned images were examined for visible defects and proper grid alignment. The intensities of the signals from each spot were quantified, and the raw data were extracted using Feature Extraction Software version 10.5.1.1 (Agilent Technologies). Quality control was performed for each of the arrays using LimmaGUI package in R from Bioconductor Software. All the arrays passed the quality control, ${ }^{34}$ but one sample was discarded as an outlier. Thus, in total, a dataset from 31 arrays was used in the next step of analysis. Data were imported into GeneMaths XT 2.12 (Applied Mathematics, Sint-Martens-Latem, Belgium) for background correction and normalization. Locally weighted linear regression (LOWESS) analysis was chosen as a normalization method, that can remove intensity-dependent effects in the $\log _{2}$ (ratio) values. ${ }^{35}$ Then, the values were $\log 2$ transformed, and the target samples (Cy5) intensities were normalized based on a reference pool (Cy3) design, as described previously. ${ }^{36}$ Target signals with an average intensity lower than two-fold above average background were discarded to increase accuracy of the data. Correction for multiple testing was not applied, as these corrections are often too strict to identify small effects, which are usually observed in nutritional studies. ${ }^{37}$ Validity of data was assured by checking biological plausibility and by independent analysis by RT-qPCR (see below) in PBMCs. Since we were interested in genes showing differential expression levels between the CR and CON groups, Student's $t$ test was performed between groups, with the first analysis between $\mathrm{CR}$ and $\mathrm{CON}$ animals. Using the significant transcripts, we next identified those showing a nonsignificant differential expression between CR-LEP and CON, representing reversion/normalization of expression. The threshold of significance for this statistical test was set at $P<.05$. Moreover, fold change (FC) calculations between groups of animals (CR vs CON, CR-LEP vs $\mathrm{CR}$, and CR-LEP vs CON) were performed. To select unique genes from duplicate probes, those sequences with higher statistical differences between $\mathrm{CR}$ and CON groups were considered. Microarray data are deposited in NCBI Gene Expression Omnibus (GEO) under accession number GSE93150.

Afterward, a statistically significant list of genes was manually analyzed taking into account their biological information, which was obtained with the use of available databases including Genecards, NCBI, UniProt, and WikiPathways, based on key biological domains, such as molecular function and biological process.
A heatmap was constructed using $\mathrm{R}$ after a range scaling method (zero-mean centered). Principal component analysis (PCA) was performed using the Excel add-in Multibase (Numerical Dynamics, Japan), with dots indicating individual samples and the ellipses representing the distribution of the groups.

\subsection{7 | Real-time quantitative RT- polymerase chain reaction (RT-qPCR) analysis}

Four genes with a signal in the array above the signal required to be quantifiable by RT-qPCR were selected to validate the microarray results: agouti related neuropeptide (Agrp), pro-opiomelanocortin (Pomc), interleukin $1 \mathrm{~b}(I l l b)$, and interleukin 10 (IllO) (see Table S1 for further details). For RT-qPCR analysis, $50 \mathrm{ng}$ of PBMC total RNA was used for reverse transcription by using iScript cDNA synthesis kit (Bio-Rad Laboratories, SA, Madrid, Spain), according to the manufacturer's protocol.

Real-time PCR was performed using the Applied Biosystems StepOnePlus Real-Time PCR System (Applied Biosystems) with Power SYBER Green PCR Master Mix (Applied Biosystems, CA, USA). Each PCR was performed from 1/5 dilution of the cDNA product and forward and reverse primers $(5 \mu \mathrm{M}$ each). All primers were purchased from Sigma Genosys (Sigma-Aldrich Química, Madrid, Spain). After an initial Taq activation at $95^{\circ} \mathrm{C}$ for 10 minutes, PCR was performed using 40 two-temperature cycles with the following cycling conditions: $95^{\circ} \mathrm{C}$ for 15 seconds and 58,60 , or $62^{\circ} \mathrm{C}$ for (as appropriate for each primer pair) 1 minute. To verify the purity of the products, a melting curve was produced after each run according to the manufacturer's instructions. The values for the threshold $(\mathrm{Ct})$ were calculated by the instrument's software (StepOne Software v2.2.2), and the relative expression of each mRNA was calculated as a percentage of male CON rats, using the $2^{-\Delta \Delta \mathrm{Ct}}$ method $^{38}$ with Ribosomal Protein L24 (Rpl24), Ribosomal Protein L41(Rpl41), and Ribosomal Protein L36a Like (Rpl36al) as reference genes. These reference genes were selected based on high expression and lowest coefficient of variation over all samples by microarray analysis.

\section{2 | Human study}

\subsection{1 | Participants}

For human verification, subjects from the BIOCLAIMS cohort were included in the present study. This cohort consists of 1310 Austrian study subjects aged 18 to 85 years, who were recruited in the BIOCLAIMS ("Biomarkers of Robustness of Metabolic Homeostasis for Nutrigenomicsderived Health Claims Made on Food") project of the 
European Commission's Framework 7 program. The study protocol was approved by the Ethics Committees of both the Medical University of Graz and Karl-Franzens University of Graz, Austria (approval numbers 23-306ex10/11 and 23324ex10/11, dated 20/05/2011; and GZ.39/46/63ex2014/15, dated 31/03/2015) and the study was conducted according to the Declaration of Helsinki. Written informed consent was obtained from all study subjects prior to study entry. The inclusion criteria for the cohort were age of 18-85 years and body mass index of $18-36 \mathrm{~kg} / \mathrm{m}^{2}$, and the exclusion criteria were any acute inflammatory diseases, immunological diseases, cardiovascular disease events in the past 6 months and malignancies in the past 6 months, as well as pregnancy. All subjects underwent comprehensive clinical and biochemical investigations. Based on these results, two subgroups of apparently healthy subjects were selected for the present study: (a) Subjects with "full health" $(\mathrm{n}=30,14$ males and $16 \mathrm{fe}-$ males), that is, without any indication of impaired health according to the comprehensive tests applied, and (b) subjects with mildly impaired metabolic health with signs of an impaired glucose homeostasis, but healthy with respect to vascular and renal biomarkers. The specific inclusion criteria for the group with full health were carotid artery intimal medial thickness $\left(\right.$ CIMT) $\leq 75$ th percentile at both sides,${ }^{39,40}$ homeostatic model assessment of insulin resistance (HOMA-IR) index $\leq 2.5^{32}$ and/or HbA1c $<38 \mathrm{mmol} / \mathrm{mol}^{41}$ and estimated Glomerular Filtration Rate (eGFR) according to the Modification of Diet in Renal Disease Study (MDRD) ${ }^{42}$ equation $>60 \mathrm{~mL} / \mathrm{min} / 1.73 \mathrm{~m}^{2}$, as well as all clinical chemistry variables (including red and white blood cell count, plasma lipids, liver function tests, plasma pancreatic enzymes, C-reactive protein, plasma total protein and albumin, iron status, and thyroid gland stimulating hormone) within the normal range $\pm 10 \%$; and not taking any medication. The group with mildly impaired metabolic health $(\mathrm{n}=26,12$ males and 14 females) had to have HOMA-IR index $>2.5$ plus HbA1c of 38-46 mmol/mol, eGFR $>60 \mathrm{~mL} / \mathrm{min} / 1.73 \mathrm{~m}^{2}$, and CIMT not $>75$ th percentile on left plus right side.

\subsubsection{Analysis of blood parameters and anthropometric assessment}

Blood was collected in the morning after an overnight fast from the antecubital vein on VacuetteVR (Greiner Bio-One, Frickenhausen, Germany) blood-collection tubes. For heparin plasma, lithium heparin coated tubes were used, which were immediately centrifuged at $1620 \mathrm{~g}$ at $4^{\circ} \mathrm{C}$ for 10 minutes. For serum, uncoated tubes were used, which were left to clot for at least 30 minutes before centrifugation at $1620 \mathrm{~g}$ at $4^{\circ} \mathrm{C}$ for 10 minutes. Plasma and serum were stored at $-80^{\circ} \mathrm{C}$ until further analysis. Blood glucose concentrations were determined photometrically on a Roche/Hitachi Cobas c Systems by a routine hexokinase enzymatic method, plasma leptin concentrations were determined by a Human Leptin Quantikine ELISA Kit (R\&D Systems, Minneapolis, MN) and serum insulin concentrations by ADVIA Centaur CP Immunoassay (Siemens Healthcare Diagnostics, Erlangen, Germany) according to the manufacturer's instructions. HOMA-IR was calculated as described above for the animal study. HbA1c was determined in red blood cells obtained from blood collected in EDTA-coated vacutainers using a fully automated HPLCbased Arkray ADAMS A1c analyzer (Menarini Diagnostics, Florence, Italy), and results were expressed as $\mathrm{mmol} / \mathrm{mol} \mathrm{Hb}$.

Anthropometric assessment was performed as described previously. ${ }^{43}$ Briefly, weight and height as well as waist circumference were measured and body fat mass $(\mathrm{kg})$ was determined using a FORANA HeliosVR bioelectrical impedance analyzer (FORANA GmbH, Frankfurt, Germany) according to standardized procedures.

\subsubsection{NPC1 gene expression in human PBCs}

From each participant, a total of $2.5 \mathrm{~mL}$ peripheral blood was collected after an overnight fast on PAXgene Blood RNA vacutainer tubes (Becton Dickinson BD DiagnosticsPreanalytical Systems, Heidelberg, Germany) via antecubital fossa venipuncture. Total RNA was isolated using the PAXgene blood RNA kit according to the manufacturer's instructions(Qiagen) and as described previously. ${ }^{3}$ Measurement of $N P C 1$ transcript levels was carried out as described above. TRIM27 (Tripartite Motif Containing 27), was chosen as reference gene. Primer sequences used for human $\mathrm{NPCl}$ were: forward, 5'-TGAAGGAAATGGTCAGATTGG-3'; reverse, 5'-GCTTGTGTTGGGAGGCTATG-3', and for TRIM27: forward, 5'- GCGGAGACTAACGTGTCGTG-3'; reverse, 5'-GGGCATCTGGTCCTGCTC-3'.

\section{3 | Statistical analysis}

Data are expressed as mean \pm SEM. The statistical analysis of microarray data has been described in detail in the above section (microarray data analysis). Statistics of the selected genes measured by RT-qPCR were computed with SPSS Statistics 24.0 (SPSS, Chicago, IL). In the animal study, statistical significances of normally distributed data were assessed by one-way ANOVA, followed by LSD post hoc tests. In the human study, box-and-whisker plots were used for graphical display and Mann-Whitney U tests for comparing the two groups. Shapiro-Wilk tests were applied to test for normal distributions, and ln-transformation was applied when required. Linear regression analysis was used to study the relation between $N P C 1$ mRNA levels and plasma leptin concentrations, 
Pearson's correlation coefficient to determine the association between ln-transformed NPCl mRNA levels and ln-transformed $\mathrm{HbAlc}$ concentrations, and Spearman rank order correlations for testing possible age dependencies of $\mathrm{NPCl}$ mRNA levels and plasma leptin concentrations. SigmaPlot version 14.0 (Systat Software, San Jose, CA) was used for statistical analysis and graphical displays in the human studies. $P<.05$ was defined as the threshold of significance.

\section{3 | RESULTS}

\section{1 | Animal study}

\subsection{1 | Phenotypic characteristics and circulating parameters}

Body weight and fat mass, both at weaning and at the age of 4 months were not significantly different between CON, CR, and CR-LEP animals (Table 1). Also, no significant differences between groups were found concerning circulating glucose, leptin, and insulin levels, nor was HOMA-IR index different, at the age of 3 months (Table 1).

\subsubsection{Gene expression in PBMCs at the age of 4 months based on whole-genome microarray analysis}

Whole genome transcriptome analysis was performed using RNA from PBMCs of 4-month-old animals from the CON,
CR, and CR-LEP groups. A $59.2 \%$ of the probes $(26,665)$ had a signal of, on average, two times above background and the corresponding mRNAs were considered expressed and analyzed further. In total, 3043 probes were found to be significantly different between CON and CR animals $(P<.05$; Student's $t$ test). Next, of these probes, differences in expression levels between CR and CR-LEP and between CR-LEP and CON were statistically tested. In total, 871 probes were significantly different between $\mathrm{CON}$ and $\mathrm{CR}$, but not statistically different between CON and CR-LEP $(P<.05$; Student $t$ test). The expression levels of these genes was negatively affected by CR during gestation, and totally or partially reversed by oral leptin treatment throughout lactation. After duplicate removal, these probes represent 484 unique genes, of which 83 genes were not annotated, and therefore, were not taken into account for the subsequent classification, nor for the heatmap or PCA representations.

The 401 remaining genes were classified into several biological processes according to their function, using the databases described in the Materials and Methods section. Of these genes, 178 were lower expressed in CR vs CON and 223 were higher expressed (Figure 1). As shown in Figure 1, the processes with the highest number of differentially expressed genes were "transcription and translation machinery," "cell turnover," "transport," "signaling," and "protein metabolism." Additional processes with a substantial number of genes were "immune system," "cytoskeleton," and "lipid metabolism." The remaining genes were related to, among others, carbohydrate metabolism, nucleic acid metabolism, and central metabolism.

Of the 401 known unique genes differently expressed in $\mathrm{CR}$ vs CON and not different between CON and CR-LEP animals, nine were identified to be also significantly different between

\begin{tabular}{|c|c|c|c|}
\hline & $\mathrm{CON}$ & $\mathbf{C R}$ & CR-LEP \\
\hline & $n=8$ & $\mathrm{n}=\mathbf{1 1}$ & $\mathrm{n}=13$ \\
\hline \multicolumn{4}{|c|}{ a. Anthropometric measurements } \\
\hline Body weight, 21 days (g) & $44.3 \pm 1.8$ & $45.9 \pm 0.6$ & $46.1 \pm 0.7$ \\
\hline Body weight, 4 months (g) & $399 \pm 10$ & $409 \pm 10$ & $402 \pm 8$ \\
\hline Fat mass, 21 days (g) & $4.2 \pm 0.3$ & $4.5 \pm 0.1$ & $4.4 \pm 0.2$ \\
\hline$(\%)$ & $9.4 \pm 0.3$ & $9.7 \pm 0.3$ & $9.3 \pm 0.5$ \\
\hline Fat mass, 4 months (g) & $56.9 \pm 3.2$ & $65.1 \pm 3.8$ & $60.4 \pm 3.2$ \\
\hline$(\%)$ & $14.3 \pm 0.7$ & $15.9 \pm 0.8$ & $14.9 \pm 0.6$ \\
\hline \multicolumn{4}{|l|}{ b. Circulating parameters } \\
\hline Glucose (mmol/L) & $5.35 \pm 0.35$ & $5.35 \pm 0.23$ & $5.41 \pm 0.17$ \\
\hline Leptin $(\mu \mathrm{g} / \mathrm{L})$ & $1.81 \pm 0.27$ & $2.99 \pm 0.46$ & $2.84 \pm 0.37$ \\
\hline Insulin $(\mu \mathrm{g} / \mathrm{L})$ & $0.49 \pm 0.06$ & $0.73 \pm 0.12$ & $0.59 \pm 0.08$ \\
\hline HOMA-IR index & $2.12 \pm 0.35$ & $3.08 \pm 0.45$ & $2.62 \pm 0.41$ \\
\hline
\end{tabular}

T A B L E 1 Anthropometric and circulating parameters in $\mathrm{CON}, \mathrm{CR}$, and CR-LEP rats

Note: CON: the offspring of control dams fed ad libitum with standard chow diet during gestation and lactation; CR: the offspring of $20 \%$ calorie-restricted dams during gestation; and CR-LEP: CR rats daily supplemented with oral leptin throughout lactation. Circulating parameters were measured at the age of 3 months under fasting conditions. Data are mean \pm SEM. No significant differences were found by one-way ANOVA $(P>.05)$ 


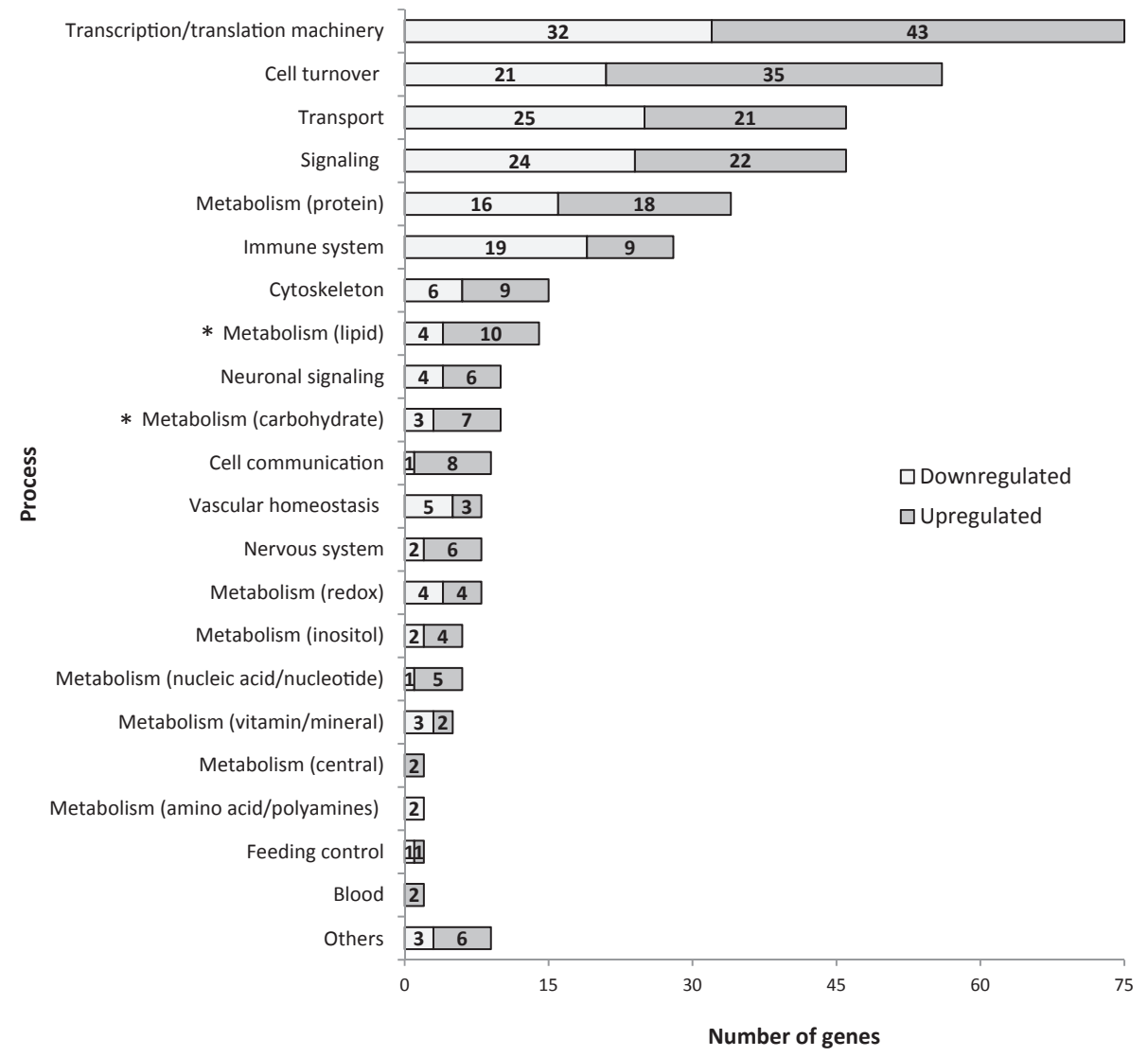

FI G URE 1 Microarray data classification into biological processes of the core group of 401 known genes differentially expressed in PBMC samples between CR and CON animals and simultaneously not different between CR-LEP and CON animals at the age of 4 months. Statistical analysis between groups was performed $(P<.05$, Student's $t$ test). The number of genes downregulated or upregulated is indicated for each group of genes. Ranking of processes is based on number of upregulated and downregulated genes. *Processes of which individual genes are presented in Table 2

CR and CR-LEP groups $(P<.05$; Student's $t$ test). These nine unique genes thus show total reversion in their differential expression upon oral leptin treatment throughout lactation, and they are: centromere protein A (Cenpa), clathrin, light chain A (Clta), F-box protein 31 (Fbxo31), hemoglobin, epsilon 1 (Hbe1), MAX network transcriptional repressor (Mnt), neurofibromin 1 (Nf1), plasminogen activator, urokinase receptor (Plaur), rennin (Ren), and regulator of microtubule dynamics 3 $(R m d n 3)$. The remaining 392 genes are genes whose expression levels differed significantly between CON and CR animals, but not between CON and CR-LEP, but also not between CR-LEP and $\mathrm{CR}$ animals. These genes thus exhibited a partial reversion upon leptin treatment throughout lactation. The expression behavior of the 401 genes is shown by heatmap (Figure 2A, Table S2) and PCA (Figure 2B) illustrating the clear distinction between CR animals and CON animals (Principal component 1), whereas CR-LEP animals appear more dispersed.

Given the link between the dysregulation of the interplay of carbohydrate and lipid metabolism and the establishment of metabolic disorders, among the genes identified in the animal study we focused on those related to carbohydrate and lipid metabolism (10 and 14 genes, respectively). A detailed description of these genes is given in Table 2. See also Figure $\mathrm{S} 1$ with the heatmap corresponding to the 24 genes included in Table 2. Among them, $\mathrm{NPCl}$ was selected to be assayed in human blood cells as a candidate gene in relation to the development of metabolic-syndrome-related disorders, because it is not only related to lipid metabolism, but it is also connected with glucose metabolism and insulin sensitivity. ${ }^{44,45}$

\section{2 | Human study}

\subsection{1 | Characteristics of study subjects}

A summary of the anthropometric and blood test results of the group with full health (control group) and the group with mildly impaired metabolic health is shown in Table 3. Mean BMI and body fat mass were significantly higher in the group with mildly impaired metabolic health, as were plasma leptin levels, which were further significantly $(P<.001)$ higher in female compared to 
(A)
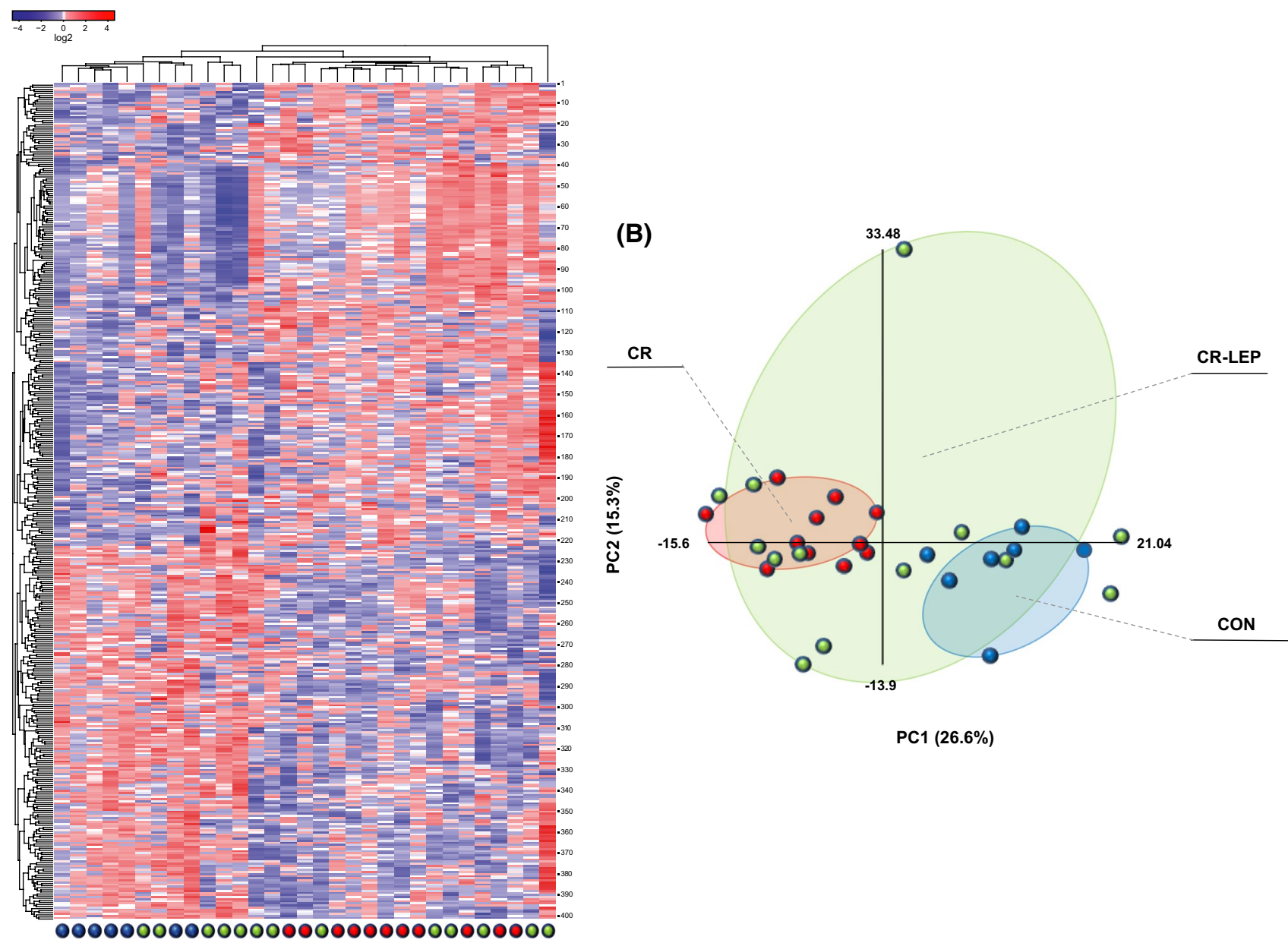

F I G U RE 2 A, Heatmap representing individual expression data of the group of 401 known genes differentially expressed in PBMC samples between CON and CR animals and simultaneously not different between CON and CR-LEP animals at the age of 4 months. Rows represent the zero-mean-centered gene expression values sorted by hierarchical clustering; the columns represent individual animals after sorting by hierarchical clustering (see Table S2 for further details). B, Principal components analysis (PCA) plot based on expression data of the group of 401 genes. CON, $\mathrm{CR}$, and CR-LEP animals are plotted based on their loading scores on the first two principal components. Confidence ellipses are drawn around each group. In both figures, CON, CR, and CR-LEP animals are indicated in blue, red, and green colors, respectively. CON: the offspring of control dams fed ad libitum with standard chow diet during gestation and lactation; CR: the offspring of $20 \%$ calorie-restricted dams during gestation; and CR-LEP: CR rats daily supplemented with oral leptin throughout lactation

male subjects, both in the group with full health (females, $\mathrm{n}=16,13.0 \pm 1.76 \mu \mathrm{g} / \mathrm{L} ;$ males, $\mathrm{n}=14,2.65 \pm 0.56 \mu \mathrm{g} / \mathrm{L})$ and mildly impaired metabolic health (females, $\mathrm{n}=14$, $30.0 \pm 4.19 \mu \mathrm{g} / \mathrm{L} ;$ males, $\mathrm{n}=12,9.85 \pm 1.71 \mu \mathrm{g} / \mathrm{L})$. According to the inclusion criteria, fasting plasma levels of glucose and insulin as well as HOMA-IR and red blood cell HbA1c were all higher in the group with mildly impaired metabolic health compared to the healthy control group (all $P<.001)$. Mean age of human subjects was 41.1 years, and the age range was between 20.4 and 74.0 years. It should be noted that the subjects with full health were younger than those with mildly impaired metabolic health; given that subjects with full health were more likely to be less prevalent at older ages in a randomly recruited cohort and age was not a selection criterion for the two groups.

\subsection{2 | Validation of NPC1 in humans}

Subjects with mildly impaired metabolic health showed decreased expression levels of NPCl in PBCs in comparison with subjects with full health $(P=.029$, MannWhitney U test) (Figure 3A). Given the age difference between the two groups (Table 3), the effect of age on $N P C l$ expression levels was studied and showed that $N C P 1$ expression levels were not related to age $(r=0.132$, $P=.350)$ (Figure 3B). Negative associations were found between expression levels of $N P C 1$ and plasma leptin levels $(r=-0.280, P=.045)$ (Figure 3C). Plasma leptin levels were not related to age $(r=0.158, P=.260)$ (Figure 3D). A negative association between expression levels of $\mathrm{NPCl}$ and $\mathrm{HbA} 1 \mathrm{c}$ levels was lost when corrected 


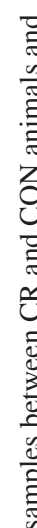

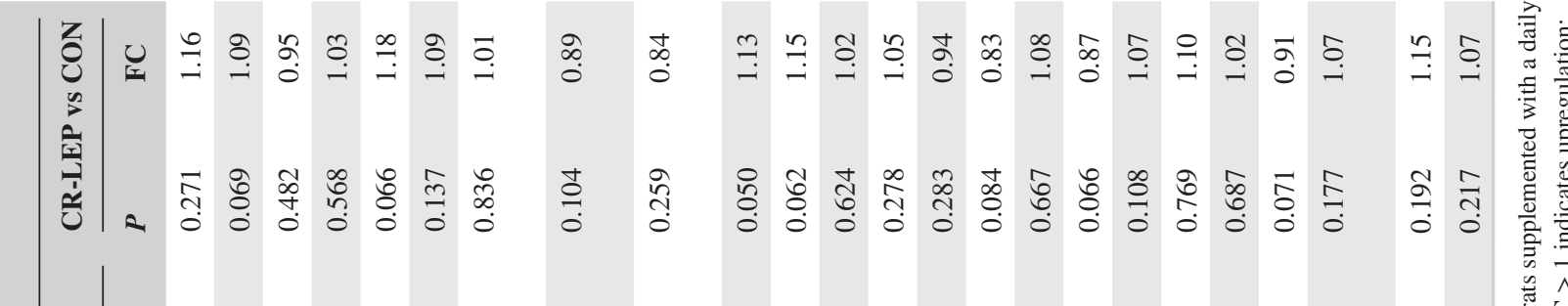
군 衰

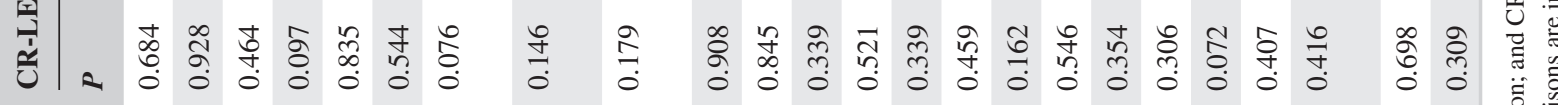

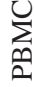

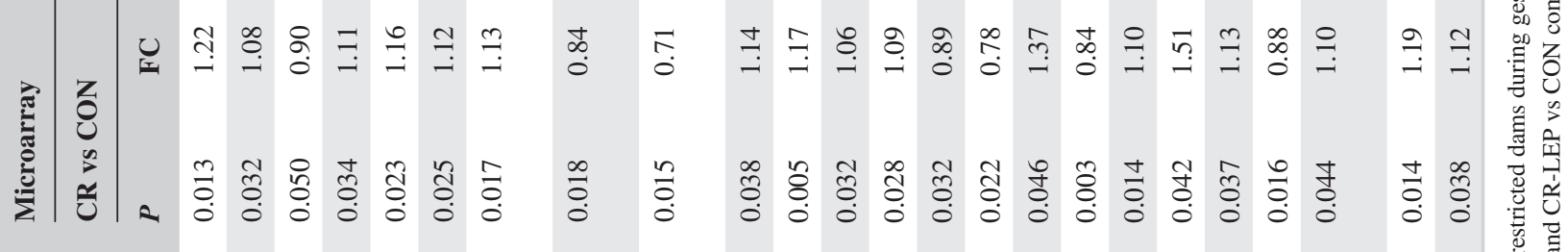

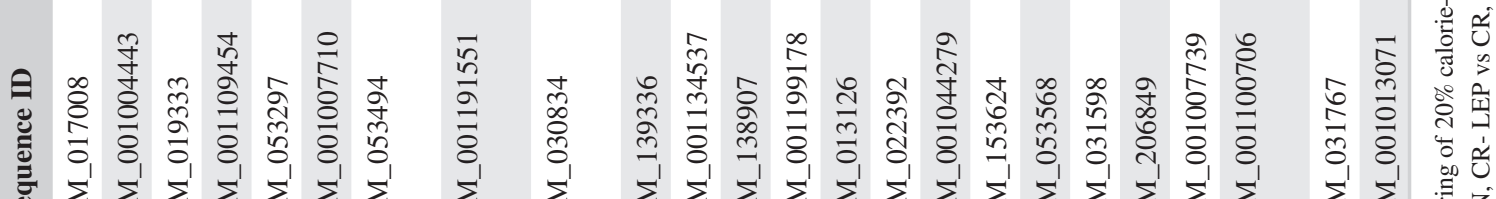

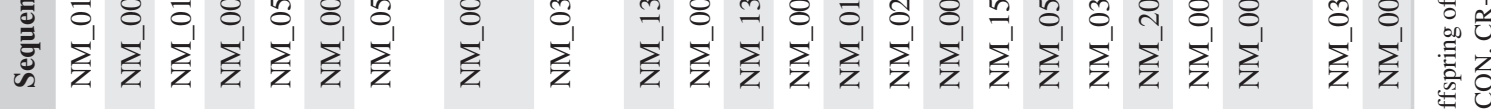

京

$\stackrel{Ð}{ \pm}$

紊
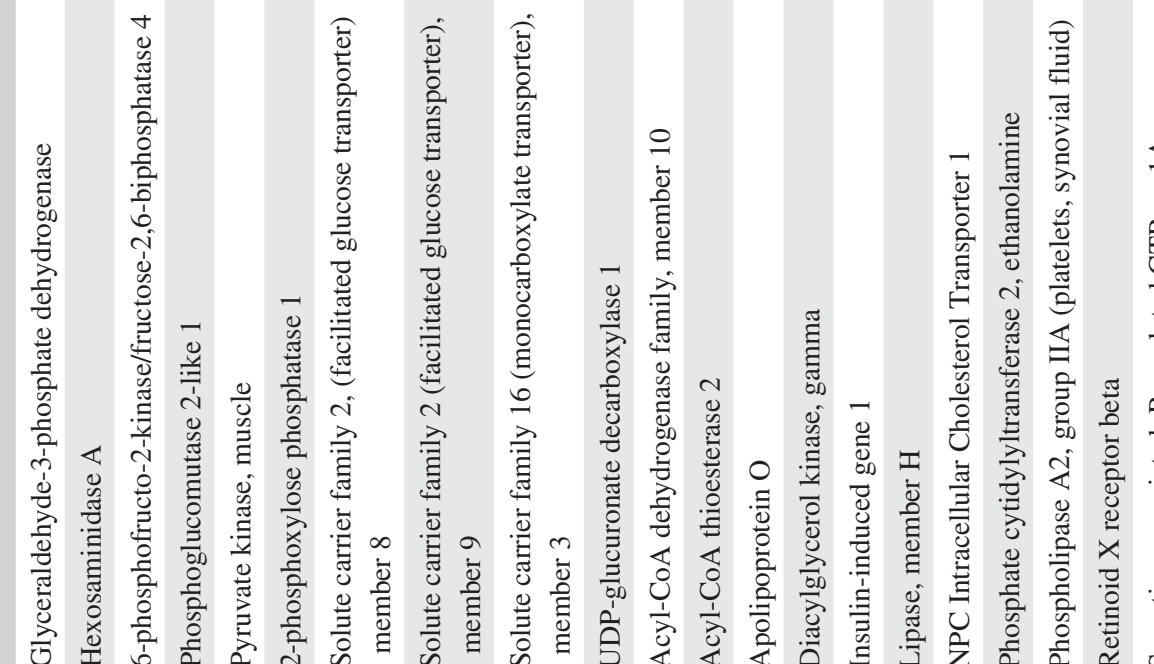

)

:

쿸 导

चี สี

苞

긍ㅇ

चี ত

悉行
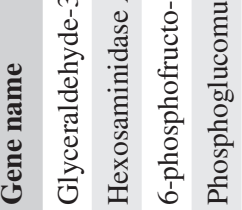

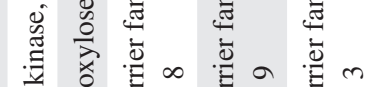

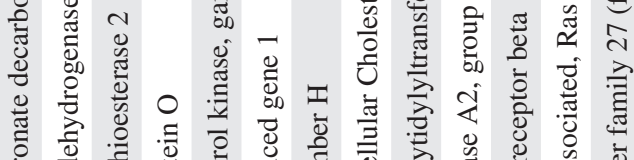

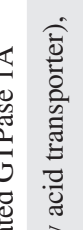
焉

व

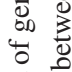

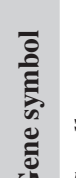

$\stackrel{\overrightarrow{0}}{=}$

马्ष

๑ั

N

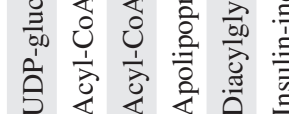
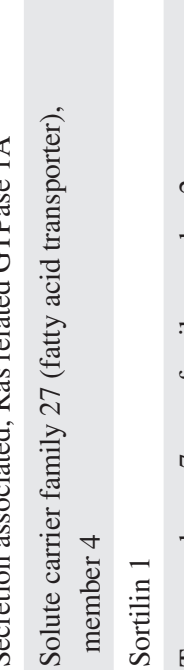
ชีّ पे 言产 


\begin{tabular}{|llll}
\hline & $\begin{array}{l}\text { Subjects with full } \\
\text { health }(\mathbf{n}=\mathbf{3 0})\end{array}$ & $\begin{array}{l}\text { Subjects with mildly } \\
\text { impaired metabolic } \\
\text { health }(\mathbf{n}=\mathbf{2 6})\end{array}$ & $\begin{array}{l}\text { Mann-Whitney } \\
\text { U test }\end{array}$ \\
\hline Age $(\mathrm{y})$ & $32.2 \pm 1.5$ & $51.4 \pm 3.1$ & $P<.001$ \\
\hline a. Anthropometric measurements & $68.7 \pm 1.87$ & $86.9 \pm 2.96$ & $P<.001$ \\
\hline Body weight $(\mathrm{kg})$ & $23.1 \pm 0.47$ & $29.5 \pm 0.84$ & $P<.001$ \\
\hline Body mass index $\left(\mathrm{kg} / \mathrm{m}^{2}\right)$ & $18.5 \pm 1.11$ & $30.6 \pm 2.07$ & $P<.001$ \\
\hline Body fat mass $(\mathrm{kg})$ & $26.9 \pm 1.39$ & $35.0 \pm 1.82$ & $P=.002$ \\
\hline Body fat mass $(\%)$ & $83.8 \pm 1.63$ & $101 \pm 1.90$ & $P<.001$ \\
\hline Waist circumference $(\mathrm{cm})$ & & $P<.001$ \\
\hline b. Circulating parameters & & $5.20 \pm 0.12$ & $P<.001$ \\
\hline Glucose $(\mathrm{mmol} / \mathrm{L})$ & $4.66 \pm 0.07$ & $20.7 \pm 3.09$ & $P<.001$ \\
\hline Leptin $(\mu \mathrm{g} / \mathrm{L})$ & $8.18 \pm 1.36$ & $17.4 \pm 1.47$ & $P<.001$ \\
\hline Insulin $(\mu \mathrm{IU} / \mathrm{mL})$ & $7.55 \pm 0.66$ & $3.94 \pm 0.29$ & $P<.001$ \\
\hline HOMA-IR & $1.57 \pm 0.15$ & $41.2 \pm 0.38$ & \\
\hline HbA1c $(\mathrm{mmol} / \mathrm{mol} \mathrm{Hb})$ & $36.0 \pm 0.56$ & &
\end{tabular}

T A B LE 3 Characteristics of the human subjects of the study

Note: Data are mean \pm SEM.

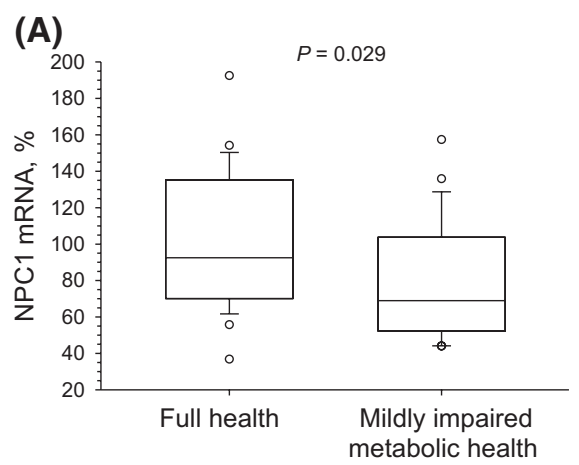

(C)

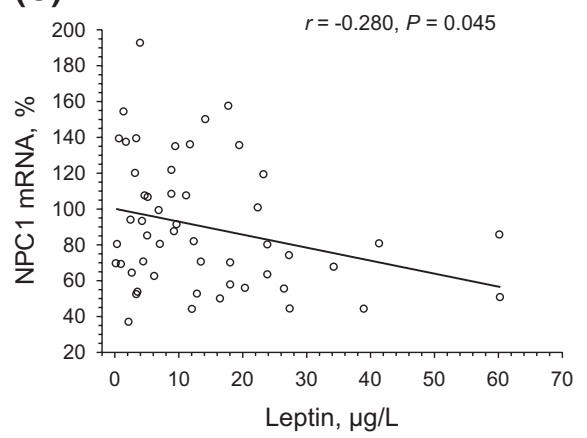

(B)

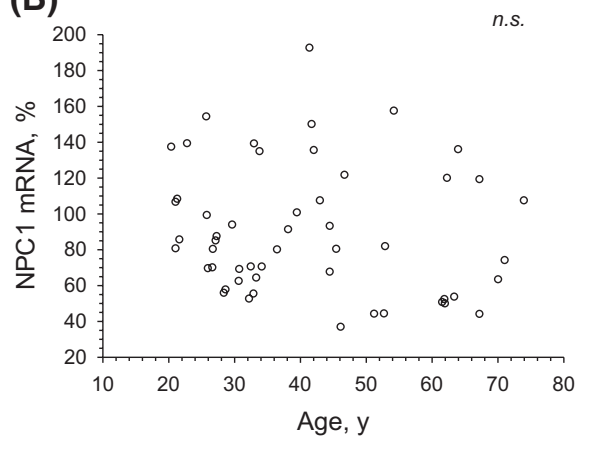

(D)

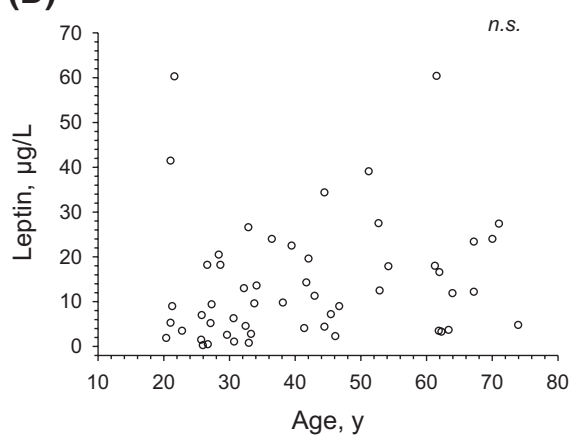

F I G U RE $3 \quad N P C 1$ expression levels in peripheral blood cells of human subjects with full health were significantly higher compared with mildly impaired metabolic health (panel A); mRNA levels determined by RT-qPCR are expressed as a percentage of the mean value of individuals with full health, and data are presented as box-and-whisker plots displaying the median, first and third quartile (box), first and third quartile plus/ minus 1.5 times the interquartile range (whiskers), as well as the 5th and 95th percentiles (individual dots). NPC1 expression levels, expressed as a percentage of the mean value of individuals with full health, were inversely related with plasma leptin levels (panel C). NPC1 expression levels (panel B) and plasma leptin concentrations (panel D), did not show age dependencies (n.s., not significant)

for significant age effects on $\mathrm{HbAlc}$ levels (data not shown). No significant differences were found between male and female subjects regarding NPCl mRNA levels in PBCs (data not shown).

\section{4 | DISCUSSION}

In the present study, we searched for genes whose expression levels in PBMCs of adult rats were affected by calorie 
restriction of their mothers during gestation and, at the same time, to assess if such alterations were totally or partially reverted by early life intervention with leptin supplementation orally taken during the suckling period. Since we were interested in finding predictive biomarkers for metabolic diseases in still healthy adults, we analyzed gene expression in 4-month old adult rats, but before the phenotypic changes related to the metabolic syndrome, as appear at the age of 6 months, were manifest. ${ }^{31}$ From this starting point, the whole genome transcriptome analysis in 4-month old rat PBMCs identified a group of 401 known genes. As anticipated, at the age of 6 months, ${ }^{31}$ the CR animals, particularly when exposed to an obesogenic diet, showed an imbalance in energy homeostasis, and displayed excess fat accumulation, insulin resistance, hypertriglyceridemia, hepatic lipid deposition, and adipose tissue inflammation. These alterations were reversed, at least in part, in CR animals that were orally given leptin during the suckling period. ${ }^{31}$ Because of the disrupted metabolism, we focused our attention to the genes related to carbohydrate and lipid metabolism, and particularly to those for which involvement in metabolic syndrome was supported by scientific literature (Apoo, Insig1, Npc1, Pcyt2, Pla2g2a, Rxrb, Slc2a8, Slc2a9, Slc27a4, and Sort1).

Slc2a8 (Solute carrier family 2, (facilitated glucose transporter) member 8) and Slc2a9 (Solute carrier family 2, (facilitated glucose transporter) member 9) belong to the solute carrier 2A family, which encode members of the facilitative glucose transporters. SLC2A8, also known as GLUT8, is a glucose and fructose transporter that is widely distributed in tissues, including liver. ${ }^{46,47}$ GLUT8 is important for hepatic fructose uptake, mediating fructose-induced de novo lipogenesis, and has been shown to be essential for fructose-induced nonalcoholic fatty liver disease. ${ }^{48}$ The function of SLC2A8 in PBMCs has not been described. SLC2A9 is also known as GLUT9 as well as the urate efflux transporter (URATv1). It is mainly expressed in kidney, liver, leukocytes, and placenta. ${ }^{49}$ This protein acts as a fructose and as a uric acid transporter, and plays a critical role in uric acid homeostasis, influencing circulating urate concentration, excretion, and gout. ${ }^{50}$ Common genetic variants of $S L C 2 A 9$ have been found to be associated with serum urate levels in Caucasian cohorts, ${ }^{51-53}$ and with increased risk for type 2 diabetes complicated with hyperuricemia in Chinese population. ${ }^{54}$

Among the group of genes related to lipid metabolism, Pcyt2 (phosphate cytidylyltransferase 2, ethanolamine), and Rxrb (retinoid X receptor beta) were both upregulated in $\mathrm{CR}$ animals compared with controls. Notably, low expression levels of Pcyt2 and Rxrb in PBMCs were previously proposed as potential markers of improved metabolic health since they were found to be downregulated in the offspring of rat dams exposed to a mild calorie restriction during lactation, ${ }^{9}$ which are less prone to develop obesity and insulin resistance under high-fat diet feeding. ${ }^{55}$ Thus, the opposite pattern of expression of both genes in animal models of impaired and improved metabolic health reinforces their potential as biomarkers.

The protein encoded by Pcyt 2 is the main regulatory enzyme in de novo biosynthesis of phosphatidylethanolamine from ethanolamine and diacylglycerol. Pcyt2 is known to play a pivotal role in processes which when deregulated could lead to the development of obesity, insulin resistance, liver steatosis, and dyslipidemia. ${ }^{56}$ However, further studies need to be done to interrogate the potential relationship between increased expression levels of this gene and the detrimental health effects described in CR animals. Regarding Rxrb, it encodes for one of the three retinoid $\mathrm{X}$ receptor (RXR) subtypes and belongs to the family of nuclear hormone receptors which are involved in, for example, mediating the effects of 9-cis-retinoic acid. RXRb heterodimerizes with, for example, peroxisome proliferator-activated receptor alpha (PPAR $\alpha)$, which together contribute to the induction of the acyl-CoA oxidase gene, which encodes the rate-limiting enzyme of peroxisomal B-oxidation of fatty acids. ${ }^{57} \mathrm{RXRb}$ may also be involved in lipogenesis, since it mediates the induction of the lipogenic enzyme fatty acid synthase via SREBP- $1 c^{58}{ }^{58}$ The higher expression levels of Rxrb in PBMCs of CR animals compared with controls could be indicative of increased lipogenesis capacity in these animals, according to the positive correlation described between expression levels of this gene in PBMCs and in white adipose tissue in adult rats. ${ }^{9}$

Another lipid metabolism-related gene is Slc27a4 (Solute Carrier Family 27 Member 4), which has been suggested to play a role in acquired obesity. ${ }^{59}$ This gene encodes SLC27A4/FATP4, a member of a family of fatty acid transport proteins involved in translocation of long-chain fatty acids across the plasma membrane and intracellular fatty acid trafficking, especially transporting adipocyte lipolysis-derived fatty acids from the lipid droplet into circulation. Here, we found increased expression levels of Slc27a4 in PBMCs of CR animals. Interestingly, expression levels of this gene in human adipose tissue were also found to be increased in obesity (independent of genetic factors), and correlated with measures of obesity and insulin resistance that are influenced by both genetic and nongenetic factors. ${ }^{59}$

Other genes related to lipid metabolism that were upregulated in CR animals have been related to cardiovascular heart disease, particularly Apoo (Apolipoprotein O), Pla2g2a (Secretory Phospholipase A2 Group IIA), and Sortl (sortilin 1). APOO was identified as a novel apoprotein overexpressed in heart tissue in a model of obesity-related hypertension induced by a high-fat diet in dogs. ${ }^{60}$ This protein was also found to be upregulated in the heart of diabetic patients. ${ }^{61}$ Further studies have demonstrated that APOO localizes in the mitochondria of cardiomyocytes and its overexpression enhances mitochondrial uncoupling and respiration, leading to mitochondrial dysfunction, lipotoxicity, and cardiomyopathy. ${ }^{62}$ 
This protein has been proposed as a signal regulator of mitochondrial function and cardiac metabolism, representing a link between impaired mitochondrial function and the onset of cardiomyopathy. ${ }^{62}$ Present results showing increased expression levels of Apoo in PBMCs of CR animals could be indicative of impaired mitochondrial function, and hence may be predictive of the altered heart function associated to obesity and diabetes. In turn, Pla2g2a encodes for a member of the phospholipase A2 family. It catalyzes the hydrolysis of the sn-2 ester bond of phospholipids found in lipoproteins and cell membranes, generating nonesterified free fatty acids and lyso-phospholipids, which may promote diverse pro-inflammatory processes. ${ }^{63}$ PLA2 type IIA is recognized for its role in chronic inflammatory diseases and generation of $\mathrm{PGE}_{2}$ and other eicosanoids after immune cell activation. ${ }^{64}$ Remarkably, Pla2g2a has been described to be upregulated in the stromal vascular cell fraction of adipose tissue in diet-induced obese rats, whereas the inhibition of PLA2 type IIA protein reversed and protected against diet-induced adiposity, insulin resistance, and other metabolic dysfunctions induced by high-fat diet. ${ }^{64}$ In humans, increased plasma concentration of PLA2 type IIA has also been associated with the risk of coronary events in various studies. ${ }^{65,66}$ The upregulation of Pla2g2a in CR animals compared to controls is thus likely associated with increased susceptibility to alterations related to the metabolic syndrome, particularly cardiovascular health. Sortilin 1, the protein encoded by the Sort1 gene, is a cellular trafficking receptor that is responsible for the transport of apoB100 to the lysosome for degradation in liver. Notably, sortilin 1 is also expressed in macrophages, where it promotes uptake of native low-density lipoprotein, foam cell formation, and atherosclerosis ${ }^{67}$ Deficient macrophage expression of Sortl has been shown to be protective against atherosclerosis, at least in part by reducing LDL uptake ${ }^{67}$; thus, the finding of increased expression levels of Sort1 in PBMCs of CR animals might be indicative of increased vascular risk, but this requires further investigation.

Other interesting genes not only related to lipid metabolism, but also with important connections with insulin homeostasis, are Insig1 (Insulin-induced gene-1) and particularly $\mathrm{Npcl}$ (NPC intracellular cholesterol transporter 1). Insig 1 encodes for an endoplasmic reticulum resident protein, which inhibits the rate-limiting enzyme in cholesterol biosynthesis, 3-hydroxy-3-methylglutaryl-CoA (HMG-CoA) reductase. It also blocks processing of SREBPs, thus preventing high-glucose-induced activation of lipid biosynthetic genes. Therefore, it plays a critical role in the feedback control of lipid synthesis. ${ }^{68}$ Overexpression of Insigl has been shown to protect $\beta$ cells against glucolipotoxicity. ${ }^{68}$ In turn, decreased Insigl mRNA expression levels have been found in white adipose tissue from obese mice with insulin resistance and from humans with morbid obesity. ${ }^{69}$ Moreover, a single-nucleotide polymorphism (SNP) in the promoter region of this gene (rs2721) has been associated with triacylglycerol (TG) levels. ${ }^{70}$ Individuals homozygous for the $\mathrm{T}$ allele showed a two-fold lower expression of INSIGI in liver biopsy samples and had 9\% higher TG levels when compared with individuals homozygous for the $\mathrm{G}$ allele. ${ }^{70}$ Taking these findings into account, decreased expression levels of this gene in CR animals compared with controls may be in accordance with alterations in lipid metabolism and predisposition to insulin resistance under a high-fat, high-glucose diet, reinforcing its use as a potential biomarker of predisposition to alterations in lipid metabolism and insulin homeostasis.

$\mathrm{Npcl}$ encodes a transmembrane protein involved in cholesterol efflux from the lysosome, but it is also related to glucose metabolism, influencing body weight, and insulin homeostasis. In humans, genetic variants within $N P C 1$ have been associated with obesity and type 2 diabetes, ${ }^{71,72}$ and rare loss-of-function $\mathrm{NPCl}$ mutations are also linked to increased risk of obesity. ${ }^{73} \mathrm{Npcl}$ haploinsufficient mice also display greater susceptibility to increased whole body and abdominal adiposity and hepatic steatosis, together with other abnormal metabolic features such as hyperleptinemia, dyslipidemia, and insulin resistance, in the absence of hyperphagia. ${ }^{44}$ Alterations associated with a deficiency in NPC1 protein have been related to an impairment of insulin signaling and insulin-mediated glucose uptake in adipocytes. ${ }^{45}$ Notably, such alterations are common with the metabolic profile of the adult offspring of gestational calorie-restricted offspring rats described by ourselves and other groups, with the outputs depending on the severity of the intervention and of postnatal (PN) dietary conditions. ${ }^{31,74}$ Hence, taken together, these results provide biological bases for the interest of blood cells transcript levels of $\mathrm{Npcl}$ as a candidate biomarker of energy homeostasis and adipocyte insulin sensitivity maintenance.

Expression levels in blood cells of the above mentioned genes identified as differentially expressed in an animal model with higher predisposition to metabolic alterations, and sensitive to early life intervention, could be of interest as candidate biomarkers for diagnosing the risk of metabolic-related pathologies in adulthood. $\mathrm{NPCl}$ is one of the most promising genes, because it is connected to both lipid and glucose metabolism and related to insulin sensitivity, therefore, it was selected to be assessed in humans.

Notably, the presence of decreased NPC1 mRNA levels in blood cells of adult subjects with mildly impaired metabolic health-particularly in relation to glucose homeostasis-but otherwise healthy, in comparison with subjects with full health, supports it as an early biomarker of increased risk of insulin resistance. As a consequence of the evolution of metabolic changes with age, subjects with impaired metabolic health were older than those with full health, mainly because those with full health were less prevalent at older ages in the randomly recruited cohort. However, and importantly, the changes in $\mathrm{NPCl}$ expression levels were not related to age. 
This biomarker, if further validated in other human studies, may allow the identification of individuals at increased risk, before disease onset becomes evident, and may be used to monitor effectiveness of interventions. To this end it should be explored (a) if and at what stage of deterioration of metabolic health changes in NPCl transcript levels occur in subjects with full health on the long term, and (b) if the changes observed in the group with metabolically impaired health, along with the lower $\mathrm{NPCl}$ transcript levels, can be reverted by well-controlled lifestyle (diet and/or physical activity) interventions.

In conclusion, functional microarray analysis of PBMCs of animal models which underwent prenatal and early PN interventions has allowed the identification of a group of genes of interest as potential candidate markers in adulthood of predisposition to alterations related to the metabolic syndrome and its reversion by nutritional intervention in early life. About 10 genes related to carbohydrate and lipid metabolism with established functional connections with insulin homeostasis, hepatic steatosis, and cardiovascular health (particularly Npc1, Apoo, Insig1, Pcyt2, Pla2g2a, Rxrb, Slc2a8, Slc2a9, Slc27a4, and Sort1) are of particular interest as potential biomarkers, especially $\mathrm{NPCl}$ which was chosen to be confirmed in humans. Its expression levels in PBCs was decreased in a group of adult volunteers with a mildly impaired metabolic health, but otherwise healthy, compared with individuals with an optimal health. The relevance of $N p c 1$, but also of the other genes identified, once validated in other human studies, lies in the possibility of early detection of an increased risk of carbohydrate metabolism-related pathologies in adults before the onset of an overt disease, with the final goal of preventing the manifestation of the disease. These genes may also be used to monitor effectiveness of early interventions using blood cells as a minimally invasive surrogate tissue.

\section{ACKNOWLEDGMENTS}

This research was supported by the European Union's Seventh Framework Programe FP72007-2013 under grant agreement n. 244995 (BIOCLAIMS Project), the Spanish Government (grants AGL2015-67019-P (MINECO/FEDER, UE) and PGC2018-097436-B-I00 (MCIU/AEI/FEDER, UE)), and the Instituto de Salud Carlos III, Centro de Investigación Biomédica en Red Fisiopatología de la Obesidad y Nutrición, CIBERobn, and the Federal Ministry of Science, Research and Economy of Austria to Karl-Franzens University of Graz (BMWF651.483/0001-II/2/2010) and Medical University of Graz (BMWF-651.484/0001-II/2/2010). The groups of A. Palou and J. Keijer are members of the European Research Network of Excellence NuGO (The European Nutrigenomics Organization, EU Contract: no. FP6-506360). Nara Szostaczuk has been granted a $\mathrm{PhD}$ fellowship entitled "beca para la formación de personal investigador," co-funded by the Regional Government (Conselleria d'Educació, Cultura i Universitats, CAIB) and the
European Social Fund (FSE). The contributions for the characterization of the study groups of J. Grabher, Clinical Division of Nephrology, Department of Internal Medicine, Medical University of Graz, Graz, Austria, are gratefully acknowledged.

\section{CONFLICT OF INTEREST}

AP, CP and JS are authors of a patent held by the University of the Balearic Islands entitled 'Use of leptin for the prevention of excess body weight and composition containing leptin' (WO 2006089987 A1; Priority data: 23 February 2005).

\section{AUTHOR CONTRIBUTIONS}

B. M. Winklhofer-Roob, J. M. Roob, J. Keijer, A. Palou, and C. Picó designed research; N. Szostaczuk, E. M. van Schothorst, J. Sánchez, T. Priego, M. Palou, M. BekkenkampGrovenstein, G. Faustmann, B. Tiran, and B. ObermayerPietsch performed research; N. Szostaczuk, E. M. van Schothorst; J. Sánchez, B. M. Winklhofer-Roob, and C. Picó analyzed data; N. Szostaczuk, E. M. van Schothorst, B. M. Winklhofer-Roob, J. Keijer, A. Palou, and C. Picó wrote the paper. All authors revised the final version of the manuscript.

\section{REFERENCES}

1. NCD Risk Factor Collaboration. Worldwide trends in body-mass index, underweight, overweight, and obesity from 1975 to 2016 : a pooled analysis of 2416 population-based measurement studies in 128.9 million children, adolescents, and adults. Lancet. 2017;390:2627-2642.

2. Musaad S, Haynes EN. Biomarkers of obesity and subsequent cardiovascular events. Epidemiol Rev. 2007;29:98-114.

3. Sanchez J, Priego T, Pico C, et al. Blood cells as a source of transcriptional biomarkers of childhood obesity and its related metabolic alterations: results of the IDEFICS study. J Clin Endocrinol Metab. 2012;97:E648-E652.

4. Afman L, Milenkovic D, Roche HM. Nutritional aspects of metabolic inflammation in relation to health-insights from transcriptomic biomarkers in PBMC of fatty acids and polyphenols. Mol Nutr Food Res. 2014;58:1708-1720.

5. Sanchez J, Pico C, Ahrens W, et al. Transcriptome analysis in blood cells from children reveals potential early biomarkers of metabolic alterations. Int J Obes (Lond). 2017;41:1481-1488.

6. de Mello VD, Kolehmanien M, Schwab U, Pulkkinen L, Uusitupa M. Gene expression of peripheral blood mononuclear cells as a tool in dietary intervention studies: what do we know so far? Mol Nutr Food Res. 2012;56:1160-1172.

7. Caimari A, Oliver P, Rodenburg W, Keijer J, Palou A. Slc27a2 expression in peripheral blood mononuclear cells as a molecular marker for overweight development. Int J Obes (Lond). 2010;34:831-839.

8. Oliver P, Reynes B, Caimari A, Palou A. Peripheral blood mononuclear cells: a potential source of homeostatic imbalance markers associated with obesity development. Pflugers Arch. 2013;465:459-468.

9. Konieczna J, Sanchez J, van Schothorst EM, et al. Identification of early transcriptome-based biomarkers related to lipid metabolism in peripheral blood mononuclear cells of rats nutritionally programmed for improved metabolic health. Genes Nutr. 2014;9:366. 
10. Diaz-Rua R, Keijer J, Caimari A, van Schothorst EM, Palou A, Oliver P. Peripheral blood mononuclear cells as a source to detect markers of homeostatic alterations caused by the intake of diets with an unbalanced macronutrient composition. J Nutr Biochem. 2015;26:398-407.

11. Hales CN, Barker DJ. The thrifty phenotype hypothesis. Br Med Bull. 2001;60:5-20.

12. Gluckman PD, Hanson MA, Pinal C. The developmental origins of adult disease. Matern Child Nutr. 2005;1:130-141.

13. Pico C, Palou M, Priego T, Sanchez J, Palou A. Metabolic programming of obesity by energy restriction during the perinatal period: different outcomes depending on gender and period, type and severity of restriction. Front Physiol. 2012;3:436.

14. Kiani A, Nielsen MO. Metabolic programming: origin of non-communicable diseases in early life nutrition. Int J Endocrinol Metab. 2011;9:409-415.

15. Vickers $\mathrm{MH}$, Breier BH, Cutfield WS, Hofman PL, Gluckman PD. Fetal origins of hyperphagia, obesity, and hypertension and postnatal amplification by hypercaloric nutrition. Am J Physiol Endocrinol Metab. 2000;279:E83-E87.

16. Palou M, Konieczna J, Torrens JM, et al. Impaired insulin and leptin sensitivity in the offspring of moderate caloric-restricted dams during gestation is early programmed. J Nutr Biochem. 2012;23:1627-1639.

17. Palou M, Priego T, Sánchez J, Palou A, Picó C. Sexual dimorphism in the lasting effects of moderate caloric restriction during gestation on energy homeostasis in rats is related with fetal programming of insulin and leptin resistance. Nutr Metab (Lond). 2010;7:69.

18. Ikenasio-Thorpe BA, Breier BH, Vickers MH, Fraser M. Prenatal influences on susceptibility to diet-induced obesity are mediated by altered neuroendocrine gene expression. J Endocrinol. 2007;193:31-37.

19. Garcia AP, Palou M, Priego T, Sanchez J, Palou A, Pico C. Moderate caloric restriction during gestation results in lower arcuate nucleus NPY- and alphaMSH-neurons and impairs hypothalamic response to fed/fasting conditions in weaned rats. Diabetes Obes Metab. 2010;12:403-413.

20. Garcia AP, Palou M, Sanchez J, Priego T, Palou A, Pico C. Moderate caloric restriction during gestation in rats alters adipose tissue sympathetic innervation and later adiposity in offspring. PLoS ONE. 2011;6:e17313.

21. Palou M, Pico C, McKay JA, et al. Protective effects of leptin during the suckling period against later obesity may be associated with changes in promoter methylation of the hypothalamic proopiomelanocortin gene. Br J Nutr. 2011;106:769-778.

22. Garcia AP, Priego T, Palou M, Sanchez J, Palou A, Pico C. Early alterations in plasma ghrelin levels in offspring of calorie-restricted rats during gestation may be linked to lower sympathetic drive to the stomach. Peptides. 2013;39:59-63.

23. Casabiell X, Pineiro V, Tome MA, Peino R, Dieguez C, Casanueva FF. Presence of leptin in colostrum and/or breast milk from lactating mothers: a potential role in the regulation of neonatal food intake. J Clin Endocrinol Metab. 1997;82:4270-4273.

24. Palou A, Pico C. Leptin intake during lactation prevents obesity and affects food intake and food preferences in later life. Appetite. 2009;52:249-252.

25. Palou M, Pico C, Palou A. Leptin as a breast milk component for the prevention of obesity. Nutr Rev. 2018;76:875-892.

26. Pico C, Oliver P, Sanchez J, et al. The intake of physiological doses of leptin during lactation in rats prevents obesity in later life. Int $J$ Obes (Lond). 2007;31:1199-1209.
27. Sanchez J, Priego T, Palou M, Tobaruela A, Palou A, Pico C. Oral supplementation with physiological doses of leptin during lactation in rats improves insulin sensitivity and affects food preferences later in life. Endocrinology. 2008;149:733-740

28. Konieczna J, Garcia AP, Sanchez J, Palou M, Palou A, Pico C. Oral leptin treatment in suckling rats ameliorates detrimental effects in hypothalamic structure and function caused by maternal caloric restriction during gestation. PLOS ONE. 2013;8:e81906.

29. Konieczna J, Palou M, Sanchez J, Pico C, Palou A. Leptin intake in suckling rats restores altered $\mathrm{T} 3$ levels and markers of adipose tissue sympathetic drive and function caused by gestational calorie restriction. Int J Obes (Lond). 2015;39:959-966.

30. Szostaczuk N, Sanchez J, Konieczna J, Palou A, Pico C. Leptin intake at physiological doses throughout lactation in male wistar rats normalizes the decreased density of tyrosine hydroxylase-immunoreactive fibers in the stomach caused by mild gestational calorie restriction. Front Physiol. 2018;9:256.

31. Szostaczuk N, Priego T, Palou M, Palou A, Pico C. Oral leptin supplementation throughout lactation in rats prevents later metabolic alterations caused by gestational calorie restriction. Int $J$ Obes (Lond). 2017;41:360-371.

32. Matthews DR, Hosker JP, Rudenski AS, Naylor BA, Treacher DF, Turner RC. Homeostasis model assessment: insulin resistance and beta-cell function from fasting plasma glucose and insulin concentrations in man. Diabetologia. 1985;28:412-419.

33. van Schothorst EM, Pagmantidis V, de Boer VC, Hesketh J, Keijer J. Assessment of reducing RNA input for Agilent oligo microarrays. Anal Biochem. 2007;363:315-317.

34. Allison DB, Cui X, Page GP, Sabripour M. Microarray data analysis: from disarray to consolidation and consensus. Nat Rev Genet. 2006;7:55-65.

35. Yang $\mathrm{YH}$, Dudoit $\mathrm{S}$, Luu $\mathrm{P}$, et al. Normalization for cDNA microarray data: a robust composite method addressing single and multiple slide systematic variation. Nucleic Acids Res. 2002;30:e15.

36. Pellis L, Franssen-van Hal NL, Burema J, Keijer J. The intraclass correlation coefficient applied for evaluation of data correction, labeling methods, and rectal biopsy sampling in DNA microarray experiments. Physiol Genomics. 2003;16:99-106.

37. Keijer J, van Helden YG, Bunschoten A, van Schothorst EM. Transcriptome analysis in benefit-risk assessment of micronutrients and bioactive food components. Mol Nutr Food Res. 2010;54:240-248

38. Pfaffl MW. A new mathematical model for relative quantification in real-time RT-PCR. Nucleic Acids Res. 2001;29:e45.

39. Stein JH, Korcarz CE, Hurst RT, et al. Use of carotid ultrasound to identify subclinical vascular disease and evaluate cardiovascular disease risk: a consensus statement from the American Society of Echocardiography Carotid Intima-Media Thickness Task Force. Endorsed by the Society for Vascular Medicine. J Am Soc Echocardiogr 2008;21:93-111; quiz 189-190.

40. Denarie N, Gariepy J, Chironi G, et al. Distribution of ultrasonographically-assessed dimensions of common carotid arteries in healthy adults of both sexes. Atherosclerosis. 2000;148:297-302.

41. American Diabetes Association. Standards of medical care in diabetes-2019. Diabetes Care. 2019;39:S1-S193.

42. Levey AS, Coresh J, Greene T, et al. Expressing the Modification of Diet in Renal Disease Study equation for estimating glomerular filtration rate with standardized serum creatinine values. Clin Chem. 2007;53:766-772. 
43. Faustmann G, Tiran B, Maimari T, et al. Circulating leptin and NFkappaB activation in peripheral blood mononuclear cells across the menstrual cycle. BioFactors. 2016;42:376-387.

44. Jelinek D, Millward V, Birdi A, Trouard TP, Heidenreich RA, Garver WS. Npc1 haploinsufficiency promotes weight gain and metabolic features associated with insulin resistance. Hum Mol Genet. 2011;20:312-321.

45. Fletcher R, Gribben $\mathrm{C}$, Ma X, et al. The role of the Niemann-Pick disease, type $\mathrm{C} 1$ protein in adipocyte insulin action. PLoS ONE. 2014;9:e95598.

46. Gorovits N, Cui L, Busik JV, Ranalletta M, de-Mouzon SH, Charron MJ. Regulation of hepatic GLUT8 expression in normal and diabetic models. Endocrinology. 2003;144:1703-1711.

47. DeBosch BJ, Chi M, Moley KH. Glucose transporter 8 (GLUT8) regulates enterocyte fructose transport and global mammalian fructose utilization. Endocrinology. 2012;153:4181-4191.

48. Debosch BJ, Chen Z, Saben JL, Finck BN, Moley KH. Glucose transporter 8 (GLUT8) mediates fructose-induced de novo lipogenesis and macrosteatosis. J Biol Chem. 2014;289:10989-10998.

49. Augustin R, Carayannopoulos MO, Dowd LO, Phay JE, Moley JF, Moley KH. Identification and characterization of human glucose transporter-like protein-9 (GLUT9): alternative splicing alters trafficking. J Biol Chem. 2004;279:16229-16236.

50. Vitart V, Rudan I, Hayward C, et al. SLC2A9 is a newly identified urate transporter influencing serum urate concentration, urate excretion and gout. Nat Genet. 2008;40:437-442.

51. Stark K, Reinhard W, Neureuther K, et al. Association of common polymorphisms in GLUT9 gene with gout but not with coronary artery disease in a large case-control study. PLOS ONE. 2008;3:e1948.

52. Wallace C, Newhouse SJ, Braund P, et al. Genome-wide association study identifies genes for biomarkers of cardiovascular disease: serum urate and dyslipidemia. Am J Hum Genet. 2008;82:139-149.

53. Ruiz A, Gautschi I, Schild L, Bonny O. Human mutations in SLC2A9 (Glut9) affect transport capacity for urate. Front Physiol. 2018;9:476.

54. Xing SC, Wang XF, Miao ZM, Zhang XZ, Zheng J, Yuan Y. Association of an Exon SNP of SLC2A9 gene with hyperuricemia complicated with type 2 diabetes mellitus in the Chinese male Han population. Cell Biochem Biophys. 2015;71:1335-1339.

55. Palou M, Priego T, Sanchez J, Torrens JM, Palou A, Pico C. Moderate caloric restriction in lactating rats protects offspring against obesity and insulin resistance in later life. Endocrinology. 2010;151:1030-1041.

56. Pavlovic Z, Bakovic M. Regulation of phosphatidylethanolamine homeostasis - the critical role of CTP: phosphoethanolamine cytidylyltransferase (Pcyt2). Int J Mol Sci. 2013;14:2529-2550.

57. Keller H, Dreyer C, Medin J, Mahfoudi A, Ozato K, Wahli W. Fatty acids and retinoids control lipid metabolism through activation of peroxisome proliferator-activated receptor-retinoid X receptor heterodimers. Proc Natl Acad Sci U S A. 1993;90:2160-2164.

58. Roder K, Zhang L, Schweizer M. SREBP-1c mediates the retinoid-dependent increase in fatty acid synthase promoter activity in HepG2. FEBS Lett. 2007;581:2715-2720.

59. Gertow K, Pietilainen KH, Yki-Jarvinen H, et al. Expression of fatty-acid-handling proteins in human adipose tissue in relation to obesity and insulin resistance. Diabetologia. 2004;47:1118-1125.

60. Philip-Couderc P, Smih F, Pelat M, et al. Cardiac transcriptome analysis in obesity-related hypertension. Hypertension. 2003;41:414-421.
61. Lamant M, Smih F, Harmancey R, et al. ApoO, a novel apolipoprotein, is an original glycoprotein up-regulated by diabetes in human heart. J Biol Chem. 2006;281:36289-36302.

62. Turkieh A, Caubere C, Barutaut $\mathrm{M}$, et al. Apolipoprotein O is mitochondrial and promotes lipotoxicity in heart. J Clin Invest. 2014;124:2277-2286.

63. Six DA, Dennis EA. The expanding superfamily of phospholipase A(2) enzymes: classification and characterization. Biochim Biophys Acta. 2000;1488:1-19.

64. Iyer A, Lim J, Poudyal H, et al. An inhibitor of phospholipase A2 group IIA modulates adipocyte signaling and protects against dietinduced metabolic syndrome in rats. Diabetes. 2012;61:2320-2329.

65. Kugiyama K, Ota Y, Takazoe K, et al. Circulating levels of secretory type II phospholipase $\mathrm{A}(2)$ predict coronary events in patients with coronary artery disease. Circulation. 1999; 100:1280-1284.

66. Hartford M, Wiklund O, Mattsson Hulten L, et al. CRP, interleukin-6, secretory phospholipase A2 group IIA, and intercellular adhesion molecule-1 during the early phase of acute coronary syndromes and long-term follow-up. Int J Cardiol. 2006;108:55-62.

67. Patel KM, Strong A, Tohyama J, et al. Macrophage sortilin promotes LDL uptake, foam cell formation, and atherosclerosis. Circ Res. 2015;116:789-796.

68. Engelking LJ, Kuriyama H, Hammer RE, et al. Overexpression of Insig-1 in the livers of transgenic mice inhibits SREBP processing and reduces insulin-stimulated lipogenesis. J Clin Invest. 2004;113:1168-1175.

69. Carobbio S, Hagen RM, Lelliott CJ, et al. Adaptive changes of the Insig1/SREBP1/SCD1 set point help adipose tissue to cope with increased storage demands of obesity. Diabetes. 2013;62:3697-3708.

70. Smith EM, Zhang Y, Baye TM, et al. INSIG1 influences obesity-related hypertriglyceridemia in humans. J Lipid Res. 2010;51:701-708.

71. Mariman EC, Bouwman FG, Aller EE, van Baak MA, Wang P. Extreme obesity is associated with variation in genes related to the circadian rhythm of food intake and hypothalamic signaling. Physiol Genomics. 2015;47:225-231.

72. Al-Daghri NM, Cagliani R, Forni D, et al. Mammalian NPC1 genes may undergo positive selection and human polymorphisms associate with type 2 diabetes. BMC Med. 2012;10:140.

73. Liu R, Zou Y, Hong J, et al. Rare loss-of-function variants in NPC1 predispose to human obesity. Diabetes. 2017;66:935-947.

74. Desai M, Babu J, Ross MG. Programmed metabolic syndrome: prenatal undernutrition and postweaning overnutrition. Am J Physiol Regul Integr Comp Physiol. 2007;293:R2306-R2314.

\section{SUPPORTING INFORMATION}

Additional Supporting Information may be found online in the Supporting Information section.

How to cite this article: Szostaczuk N, van Schothorst EM, Sánchez J, et al. Identification of blood cell transcriptome-based biomarkers in adulthood predictive of increased risk to develop metabolic disorders using early life intervention rat models. The FASEB Journal. 2020;34:9003-9017. https://doi.org/10.1096/fj.202000071RR 